\title{
N3c Stage Finding
}

National Cancer Institute

\section{Source}

National Cancer Institute. N3c Stage Finding. NCI Thesaurus. Code C48717.

A general term that refers to a TNM finding of cancer metastases in multiple lymph

nodes. The definition of N3c TNM finding depends on the specific type of cancer that it

refers to; for example, for breast cancer it refers to metastases in ipsilateral supraclavicular lymph nodes. 